\title{
Effect of clay content on the morphological, thermo-mechanical and chemical resistance properties of propionic anhydride treated jute fiber/polyethylene/nanoclay nanocomposites
}

\author{
Md. Faruk Hossen ${ }^{\mathrm{a}, *}$, Sinin Hamdan ${ }^{\mathrm{b}}$, Md. Rezaur Rahman ${ }^{\mathrm{a}}$, Md. Saiful Islam ${ }^{\mathrm{c}}$, Fui Kiew Liew ${ }^{\mathrm{b}}$, \\ Josephine Chang hui Lai ${ }^{\mathrm{a}}$, Md. Mizanur Rahman ${ }^{\mathrm{b}}$ \\ a Department of Chemical Engineering and Energy Sustainability, Faculty of Engineering, Universiti Malaysia Sarawak, 94300 Kota Samarahan, Sarawak, Malaysia \\ ${ }^{\mathrm{b}}$ Department of Mechanical and Manufacturing Engineering, Faculty of Engineering, Universiti Malaysia Sarawak, 94300 Kota Samarahan, Sarawak, Malaysia \\ ${ }^{c}$ Department of Chemistry, Faculty of Science, University Putra Malaysia, 43400 Serdang, Selangor, Malaysia
}

\section{A R T I C L E I N F O}

\section{Article history:}

Received 22 June 2015

Received in revised form 3 May 2016

Accepted 5 May 2016

Available online 6 May 2016

\section{Keywords:}

Montmorillonite

Jute nanocomposites

Morphology

Thermo-mechanical properties

Chemical resistance

\begin{abstract}
A B S T R A C T
Nanoclay is considered potential nanofiller for the manufacturing of natural fiber nanocomposites. The hydrophilic nature of natural fibers affects negatively its adhesion to hydrophobic polymer matrix. In the present study, propionic anhydride (PA) treated jute were used for the manufacturing of jute/ polyethylene/nanoclay nanocomposites. Different amount (wt\%) of montmorillonite (MMT) were used as nanofiller in order to optimize the nanoclay in the composite system. Finally, the nanocomposites were prepared using hot press machine at 5, 10, 15, and $20 \mathrm{wt} \%$ fiber loadings. Fourier transform infrared (FTIR) spectroscopy, scanning electron microscopy (SEM), tensile tests, thermogravimetric analysis (TGA), differential scanning calorimetry (DSC), and chemical resistance test were used to evaluate the morphological, thermo-mechanical and chemical resistance properties of the composites.
\end{abstract}

(c) 2016 Elsevier Ltd. All rights reserved.

\section{Introduction}

Nowadays, the development of natural fiber reinforced composites is one of the high attractive research fields. Jute performs relatively better properties among the other natural fibers like banana, cotton, coir, sisal, etc., due to the inexpensive and commercial availability in a required form. It can also be substituted for conventional fibers in many applications and has been applied as reinforcement to eco-composites and bio-composites [1]. The hydrophilic nature of natural fibers affects negatively its adhesion to hydrophobic polymeric matrices. To improve the compatibility between both components a surface modification has been proposed. Esterification is a common surface modification technique that has been reported to overcome the incompatible surface polarities between the natural fiber and polymer matrix [2]. Many chemical agents such as acetic anhydride, oleoyl chloride, hexanoic acid, dodecanoic acid, octadecanoic acid and docosanoic acid have been used for esterification to improve dispersion and adhesion [3-5]. During treatment, the chemical agents can react with the $\mathrm{OH}$ groups at C-2, C-3 and C6 positions of the cellulose in the fibers.

\footnotetext{
* Corresponding author.

E-mail address: fhossen.chem@gmail.com (M.F. Hossen).
}

Due to the steric effect, the bulky chemical groups can react either with the hydroxyl group at C-2 or C-3 but cannot react with $\mathrm{OH}$ groups in both positions at a time [6]. Thus, in this study, propionic anhydride (PA) has been used as coupling agent for esterification of the jute fibers to improve the interfacial interaction with polymer matrix. The matrix phase plays an important role in the performance of polymer composites. Polyethylene has outstanding properties like low density, low cost, good flex life, excellent surface hardness, scratch resistance and admirable electrical insulating properties [7]. In the case of thermoplastic composites, the dispersion of the fibers in the composites is also an important parameter to achieve consistency in the product. Jute-polyethylene composite has showed remarkable increase in mechanical properties [8]. As jute is abundantly available in South Asia such as Bangladesh, India and China, it is worthwhile to analyze the effect of surface treatments on jute fibers, i.e. on the mechanical, thermal and environmental performance of the composites produced with polyethylene (PE) matrix.

Recently, Nano-materials showed a significant performance into the composite system. It has been reported that the addition of a small amount of nanoparticle into a matrix can improve thermal and mechanical properties considerably without compromising the weight or processability of the composite [9]. Montmorillonite (MMT) incorporated polymer composites and 